\title{
Rural-urban variation in characteristics among prostate cancer patients
}

\author{
Boda Guo ${ }^{1,2}$ (D) Ming Liu ${ }^{1,2}$ (D)
}

Received: 15 November 2020 / Accepted: 23 November 2020 / Published online: 3 January 2021

๑) Springer-Verlag GmbH Germany, part of Springer Nature 2021

\section{Dear Editor,}

With considerable interest, we read the article published by Stolzenbach et al. [1], who compared stage and cancerspecific mortality (CSM) of prostate cancer ( $\mathrm{PCa}$ ) patients with different residency status. This particular topic is an important clinical issue. As such, there are a few points that we would like to bring up.

1. The factors extracted by the authors from the SEER database (2004-2016) include clinical T stage and clinical N stage. However, according to the SEER Program [2], the "clinical stage" variable was not provided in the dataset until 2016. Therefore, for patients diagnosed before 2016, it was impossible for researchers to identify the clinical stage. How to obtain the clinical stage of patients diagnosed between 2004 and 2016 needs to be explained in detail.

2. Some of the patients included in the analysis received chemotherapy. This type of treatment should be taken into consideration since previous literature showed that chemotherapy holds great potential in the management of PCa patients $[3,4]$.

3. Their study included patients with primary PCa but did not exclude multiple primary cancers. However, a prior SEER-based study demonstrated there were at increased risk for cancers of soft tissue including heart, bladder, kidney, and endocrine system among PCa men

This comment refers to the article available online at https://doi. org/10.1007/s00345-020-03483-7.

Ming Liu

liumingbjhu@126.com

1 Department of Urology, Beijing Hospital, National Center of Gerontology, Institute of Geriatric Medicine, Chinese Academy of Medical Sciences, Beijing 100730, China

2 Graduate School of Peking, Union Medical College, Beijing 100730, People's Republic of China compared with the general population, which may affect patients' survival [5].

Authors' contribution BDG: reviewed the relevant study and drafted this letter. ML: revised this letter for critical content and scientific rigour.

Funding None.

\section{Compliance with ethical standards}

Conflict of interest The authors declare that they have no conflict of interest.

\section{References}

1. Stolzenbach LF, Deuker M, Collà-Ruvolo C, Nocera L, Tian Z, Maurer T, Tilki D, Briganti A, Saad F, Mirone V, Chun FKH, Graefen M, Karakiewicz PI (2020) Differences between rural and urban prostate cancer patients. World J Urol. https://doi. org/10.1007/s00345-020-03483-7

2. Ruhl J, Adamo M, Dickie L. (February 2016). SEER Program Coding and Staging Manual 2016: Section V. National Cancer Institute, Bethesda, MD 20850-9765.

3. Quinn DI, Sandler HM, Horvath LG, Goldkorn A, Eastham JA (2017) The evolution of chemotherapy for the treatment of prostate cancer. Ann Oncol 28(11):2658-2669. https://doi. org/10.1093/annonc/mdx348

4. Saad F (2015) Prostate cancer in 2014: the year chemotherapy finally gets some respect! Nat Rev Urol 12(2):71-72. https://doi. org/10.1038/nrurol.2014.362

5. Davis EJ, Beebe-Dimmer JL, Yee CL, Cooney KA (2014) Risk of second primary tumors in men diagnosed with prostate cancer: a population-based cohort study. Cancer 120(17):2735-2741. https ://doi.org/10.1002/cncr.28769

Publisher's Note Springer Nature remains neutral with regard to jurisdictional claims in published maps and institutional affiliations. 